\title{
Estrategias pedagógicas para mejorar las habilidades lectoras y escritoras
}

\author{
Eneyda López Zamudio* \\ María Inés Puerto Hurtado ${ }^{*}$ : \\ Olga Najar Sánchez ${ }^{* * *}$
}

Artículo de reflexión

Fecha de Recepción: 3 julio 2018.

Fecha de Aprobación: 2 noviembre 2018.

\section{Resumen}

El proyecto surge a partir de la necesidad de trabajar estrategias pedagógicas significativas en el aula con el fin de potenciar las habilidades comunicativas en los estudiantes de los grados segundo y tercero. En el entorno escolar se evidencia falta de interés y motivación en estos aspectos para el desarrollo de las competencias comunicativas. Partiendo de esta necesidad, se tiene como propósito contribuir al fortalecimiento de las habilidades lectoras y escritoras en los estudiantes enfatizando en la comprensión y producción oral y escrita; para ello, se recorren varias etapas para leer y escribir de manera independiente, continúan enriqueciendo la oralidad, con la interlocución con pares, análisis de un tema, respetan turnos del habla y expresan ideas y opiniones con orden y claridad. Se aborda desde la metodología de Investigación Acción; enfoque cualitativo, la cual, permite mejorar las prácticas educativas por medio de estrategias pedagógicas significativas. La técnica utilizada fuela secuencia didáctica, para su desarrollo se implementaron talleres en las áreas básicas: lenguaje, Matemáticas, Ciencias Naturales y Ciencias Sociales. Se abordó a Díaz y Hernández (2002) quienes plantean crear ayudas pedagógicas acordes a las necesidades de los estudiantes; mediante estimular, promover y orientar la lectura y escritura significativa como forma de lograr innovación en el aula (Pulido, Najar \& Guesguan, 2016).

Palabras claves: Habilidades lectoras y escritoras, comprensión y producción oral y escrita, secuencia didáctica, aprendizaje significativo.

\footnotetext{
* Institución Educativa

Técnica La Libertad, Sede Libertad - Boyacá -

Colombia

eneyd08@yahoo.es

** Institución Educativa

Técnica La Libertad, Sede

Peña De Águilas - Boyacá -

Colombia

minespuerto2014@gmail.

com

*** Universidad Pedagógica

y Tecnológica de Colombia

- Boyacá - Colombia

olga.najar@uptc.edu.co
}

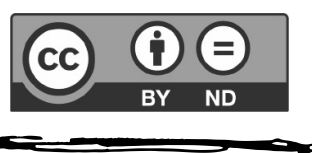




\section{Introducción}

El aprendizaje de la comprensión y producción oral y escrita durante los grados segundo y tercero es un proceso de construcción permanente. Durante el grado segundo se debe afianzar la adquisición del código escrito, las funciones gramaticales, se debe lograr que los estudiantes estén en capacidad de: analizar, comprender, interpretar, reflexionar, evaluar y producir textos orales y escritos, mediante identificación de su estructura, funciones y sus elementos; esto con propósito de potenciar la competencia comunicativa y construir nuevos conocimientos que les permita intervenir activamente en el entorno.

Como estrategia institucional, desde el año 2015, se implementó el Proyecto Institucional de Lectura y Escritura PILE con el cual, se pretende desarrollar en el estudiante competencias básicas para las diferentes áreas como la correcta expresión oral y escrita, gusto por la lectura, expresión con coherencia y cohesión de sentimientos, opiniones, deseos y reflexiones, a través de fomentar hábitos lectores y escritores en los diferentes estamentos de la comunidad educativa. No obstante, se evidencia en los estudiantes su desinterés frente a la lectura, y a la producción de textos.

La investigación surge de la necesidad de mejorar el nivel de desempeño de las competencias lectoras y escritoras de los estudiantes de la Institución Educativa Técnica La Libertad, teniendo en cuenta el bajo desempeño presentado en las habilidades comunicativas, lectoras $\mathrm{y}$ escritoras en los últimos años, en todas las áreas del conocimiento pese a las diversas actividades desarrolladas con los estudiantes en todos los niveles escolares. Este es un problema que se presenta a nivel global en las instituciones educativas, tanto en Colombia como en otros países, según lo dan a conocer los antecedentes encontrados con respecto a este tema, donde los autores aportan los conocimientos adquiridos en sus investigaciones.

El propósito de la investigación es contribuir al fortalecimiento de las habilidades lectoras y escritoras: la producción y comprensión oral y escrita en los estudiantes de los grados segundo y tercero de las sedes Peña de Águilas y Libertad de la IET La Libertad.

Para esta investigación se tomó como base algunas investigaciones realizadas en instituciones educativas de diferentes lugares, donde se han encontrado problemas de lectura y escritura, lo cual se ha convertido en un problema, pues influye de forma negativa en el desempeño académico de los estudiantes. Los autores analizados proponen estrategias para contribuir a mejorar en cuanto a lectura y escritura desde una perspectiva sociocultural para así superar las deficiencias, facilitando el desarrollo de habilidades lectoras y escritoras, para que los estudiantes aprendan significativamente desde sus contextos sociales y culturales.

Con relación al marco teórico se tomaron las referencias teniendo en cuenta las categorías de comprensión y producción oral y escrita, aprendizaje significativo, habilidades lectoras y escritoras y estrategias pedagógicas. En cuanto a la comprensión oral y escrita 
los autores se refieren a la lectura y la escritura como prácticas socioculturales y lingüísticas, y a la cultura escrita y en general el uso de la lectura y la escritura como prácticas sociales. Acerca del aprendizaje significativo los autores hacen referencia a que se deben tomar los conocimientos y experiencias que los estudiantes ya tienen (saberes previos), para conectarlos con los nuevos conocimientos, así ellos le encuentren sentido y significado a lo que se les enseña. Las estrategias pedagógicas permiten que los estudiantes interpreten y produzcan individualmente, como también en grupo, relacionándose con sus compañeros y con el docente al realizar sus propias creaciones. Para esto se tuvo en cuenta a autores como Ferreiro \& Teberosky (1979), Ferreiro (2000), Cassany (1999), Ávila (2009) Cassany (2006, 2009), Díaz \& Hernández (2002) estos autores presentan propuestas referentes a la lectura y la escritura teniendo en cuenta el entorno sociocultural de los estudiantes. Para el aprendizaje significativo y las estrategias pedagógicas se tuvo como referencia autores como: Díaz \& Hernández (2000, 1999) y Ausubel (2002), quienes aportaron sus ideas en relación con tener en cuenta los conocimientos previos de los estudiantes para conectarlos con los nuevos conocimientos para obtener el aprendizaje con sentido y significado por medio de estrategias pedagógicas ya que de esta forma se logra la motivación que los estudiantes requieren para aprender por sí solos.

Se utiliza como metodología la Investigación Acción; puesto que, permite mejorar las prácticas educativas por medio de estrategias pedagógicas significativas, que contribuyan en el desarrollo y fortalecimiento de habilidades en los estudiantes de básica primaría de la IET La Libertad. Para lo cual se tendrá en cuenta los aportes de John Elliot (1990) cuando señala que: "la investigación-acción es la reflexión que sistemáticamente se plantea en y sobre la práctica, considerando aquí ésta como una hipótesis: así se actúa en orden a probar ciertas presunciones/ conjeturas para resolver un problema práctico, además, lleva a experimentar practicando, probando así mismo estrategias en la práctica, comprobando los puntos conflictivos que existen en la clase. Así la investigación-acción es un tipo de acción reflexiva, es reflexión en la acción. (Elliot, 1990, pág. 65). La investigación se realizó en tres etapas: diagnóstico diseño e implementación y análisis de información y resultados.

Los instrumentos que se emplearon fueron las pruebas de entrada y de salida y secuencia didáctica, donde se plantearon actividades de comprensión y producción oral y escrita articuladas con las diferentes áreas: lengua castellana, matemáticas, ciencias naturales y ciencias sociales; con el fin de fortalecer los procesos de comprensión y producción teniendo como referencia las habilidades y micro habilidades planteadas en las mallas curriculares del ministerio de educación para lenguaje del grado tercero. La secuencia se evaluó mediante la rúbrica de análisis.

La muestra poblacional está conformada por 30 estudiante; 10 estudiantes de la sede Peña de Águilas del grado segundo
Las estrategias pedagógicas permiten que los estudiantes interpreten y produzcan individualmente, como también en grupo, relacionándose con sus compañeros y con el docente al realizar sus propias creaciones. Para esto se tuvo en cuenta a autores como Ferreiro \& Teberosky (1979), 
y 20 estudiantes de la sede Libertad del grado tercero. De los resultados de la prueba de entrada se seleccionaron como muestra intencionada tres (3) estudiantes de la Sede Peña de Águilas y cuatro (4) estudiantes de la Sede Libertad para un total de siete (7) estudiantes, teniendo como criterio las valoraciones obtenidas en cada uno de los niveles de desempeño (avanzado, satisfactorio, mínimo e insuficiente).

En relación al desarrollo de la propuesta se diseñaron y aplicaron los siguientes instrumentos, los cuales permitieron tener información pertinente y adecuada para el proceso investigativo. Para llegar a proponer la estrategia significativa:

Fases: La investigación se desarrolló en tres etapas como se describen a continuación:

Diagnóstico: En esta fase se realizaron las siguientes actividades: lectura, interpretación y análisis del ISCE del año 2016, revisión y análisis de estrategias institucionales, revisión bibliográfica, definición de la población objeto de estudio, diseño, aplicación y análisis de la prueba de entrada, y por último, diseño rubrica de análisis con el propósito de identificar habilidades lectoras y escritoras.

Diseño e implementación: Se diseñó e implementó una secuencia didáctica con actividades en las áreas de Lengua Castellana, Matemáticas, Ciencias Naturales y Ciencias Sociales, prueba de salida y análisis de las rubricas.

Análisis de información y resultados: Se realizó la recolección de la información del trabajo de campo, así como el análisis e interpretación de los resultados obtenidos en el desarrollo de la secuencia.

La observación directa: se recolectó la información a través de la observación directa a los estudiantes del grado 3.1 de la Sede Libertad y los estudiantes del grado segundo Sede Peña de Águilas; allí se observó especialmente a los estudiantes seleccionados mientras desarrollaban la prueba de entrada, prueba de salida y la secuencia didáctica, estas observaciones fueron registradas en los diarios de campo, donde se describió el comportamiento y acciones de cada estudiante, luego se analizó teniendo en cuenta la rúbrica de análisis.

Prueba de entrada y prueba de salida: Se diseñó con el propósito evaluar los niveles iniciales de comprensión y producción oral y escrita de los estudiantes de los grados segundo y Tercero de la sede Libertad y Peña de Águilas; teniendo en cuenta los derechos básicos de aprendizaje, lineamientos curriculares, las mallas curriculares emitidas por el MEN para el grado tercero y los fundamentos teóricos de diferentes autores. También se aplicó la prueba piloto con los estudiantes del grado tercero dos (3.2) de la Sede Libertad quienes presentan características similares a la población muestra, de esta forma se evidenció que las pruebas funcionaban para nuestra población muestra.

Rúbricas de análisis: Diseñada a partir de las mallas de aprendizaje propuestas por el Ministerio de Educación para Lenguaje de grado tercero en procesos 
de comprensión oral y escrita, habilidad, microhabilidad y los niveles de desempeño (avanzado, satisfactorio, mínimo e insuficiente), tenidos en cuenta para evaluar la prueba entrada, secuencia aplicada y la prueba de salida.

Secuencia Didáctica: Se diseñaron cuatro talleres teniendo en cuenta los Estándares Básicos de Competencias y los Derechos Básicos de Aprendizaje del lenguaje, mallas de aprendizaje Lenguaje Grado tercero propuestos por el MEN y los Fundamentos teóricos de diferentes autores. Se aplicaron a la muestra poblacional y se analizó lo referido a la muestra intencionada.

En cuanto a los resultados después de implementar la secuencia didáctica y evaluar los niveles finales en la muestra poblacional se evidenció un avance significativo en la compresión, predicción de hechos, identificar información implícita y explícita en un texto, en su gran mayoría identifican la clase de texto que leen, sus partes y características, relacionan personajes, con los hechos y contextos. Algunos infieren significados los clasifica y defienden sus ideas ante sus compañeros; sus producciones escritas organizan ideas y tratan de usar los conectores de forma adecuada, en algunos casos se evidenció que el lenguaje usado es el que usan en su diario vivir y con base a ello organizan y escriben sus producciones; su producción oral se evidencia en algunos timidez al participar en conversaciones.

\section{Referente teóricos}

Como referentes teóricos que sustentan la investigación tenemos a Emilia
Ferreiro, Daniel Cassany, David Ausubel, Frida Díaz Barriga y Gerardo Hernández. Se trabaja desde diferentes categorías las cuales serán abordadas a continuación:

\section{La Compresión y producción oral y escrita}

La mayoría de los autores que investigan sobre las lectura y la escritura siguen modelos elaborados para expertos, encontrando descripciones simples de cómo leen y escriben los estudiantes en sus primeros años escolares; Emilia Ferreiro (1979) afirma que "en lugar de un niño que espera pasivamente el reforzamiento externo de una respuesta producida poco menos que al azar, aparece un niño que trata activamente de comprender la naturaleza del lenguaje que se habla a su alrededor, y que, tratando de comprenderlo, formula hipótesis, busca regularidades, pone a prueba su anticipaciones, y se forja su propia gramática", encontrando en el aula de clase el espacio para reforzar los aprendizajes previos y realizar nuevas construcciones.

En el Congreso Mundial de Lectoescritura, celebrado en Valencia, Ana Teberosky (2002) afirma que "los niños que ya han comenzado el proceso de comprensión de lo escrito necesitan comprender para aprender: comprender cómo funciona el sistema alfabético, comprender la relación entre lenguaje oral y lenguaje escrito, comprender cuáles son las unidades específicas de lo escrito para aprender a leer y escribir", esto reflejado en la prueba de entrada, al estudiante $\mathrm{P} 1{ }^{1}$ "se le observa inseguridad
1 Estudiante de la sede Peña de Águilas, tomado de la muestra intencionada. 
al momento de analizar la información, está atento a lo que hace el compañero para copiarle y responder", evidenciando su falta de comprensión, frente al estudiante $\mathrm{G}^{2}$ quien "en el desarrollo de la secuencia, responde adecuadamente a las preguntas, utilizando la información que encuentra, tiene un orden y una secuencia en el análisis”.

En cuanto a la lectura y escritura, partimos de algunos conceptos de Emilia Ferreiro (2009) quien dice que: "la actividad de leer no da un resultado: ella no introduce ninguna modificación con el objeto que acaba de ser leído. La voz puede acompañar esta actividad, pero ella también puede desarrollarse en silencio; en caso de que la voz sea audible, es necesario también aprender a distinguir el habla que resulta de la lectura, de otros actos de habla”, en la investigación expuesta los estudiantes presenta diferencias marcadas de acuerdo al entorno social $\mathrm{y}$ de las dificultades individuales que presentan según su desarrollo cognitivo. De igual forma, en la escritura Ferreiro (2009) reitera que "la actividad de escribir deja un resultado observable; una superficie sobre la cual se escribe es transformada por esta actividad, las marcas que resultan de esta actividad son permanentes, a menos que otra acción las destruya", permitiendo desde los primeros años en el aula marcar aspectos positivos en el estudiante que usará para la vida en su relación con el medio donde se desenvuelva.

2 Estudiante de la sede El Gacal, tomado de la muestra intencionada.
De acuerdo a esto, otros autores como Daniel Cassany (1999) manifiesta que la escritura tiene una relación estrecha con la vida y la escuela, "estamos abocados a escribir. Recordamos nuestra edad porque registramos la fecha de nacimiento, existimos legalmente porque tenemos un carnet escrito que lo certifica, poseemos propiedades y realizamos actividades con el visto bueno de escrituras y contratos; nuestras posibilidades de vida y desarrollo sociocultural dependen en buena medida de la escolarización y ésta indudablemente de la capacidad de leer y escribir”, enfatizando que es la escuela quien motiva, promueve y da las pautas al estudiante para fortalecer las habilidades comunicativas; igualmente, ratificado por Ávila (2009) quien refiere sobre las competencias que son necesarias tener presentes en el desarrollo de la lectoescritura, como "la comprensión oral, la expresión oral, la comprensión lectora y la expresión escrita”.

\section{Habilidades lectoras y escritoras}

En los procesos de enseñanza y aprendizaje, el desarrollo de las habilidades lectoras y escritoras son una herramienta primordial para el trabajo transversal con las diferentes áreas del conocimiento. Para la presente investigación tomamos a Frida Díaz Barriga Acero y Gerardo Hernández desde la perspectiva constructivista, su visión de "las estrategias pedagógicas de enseñanza como medios o recursos para prestar la ayuda pedagógica ajustada a las necesidades de progreso de la actividad constructiva de los alumnos; el docente debe poseer un bagaje amplio de estrategias, conociendo qué función tienen y cómo pueden utilizarse o desarrollarse apropiadamente.” (Diaz, 2002, p. 141) 
Clasifican las estrategias de enseñanza en momentos de uso y presentación: un inicio (preinstruccional) por lo general preparan y alertan al estudiante en el qué y cómo va a aprender, las experiencias previas en busca de que se ubique en el contexto y a su vez se generen expectativas para adquirir conocimientos nuevos; un durante (coinstruccionales) donde el estudiante mejore la codificación y la conceptualización, y organice, estructure $\mathrm{e}$ interrelacione las ideas principales que se exponen en el aprendizaje; y un término (postinstruccionales) donde el estudiante forma una visión sintética, integral y critica de su propio aprendizaje.

Entre las estrategias más efectivas para mediar el aprendizaje de la lectura y escritura, Emilia Ferreiro (1979) destaca el juego, "así como el favorecimiento de actividades entre personas que se encuentran en niveles de conceptualización cercanos, lo cual beneficia las construcciones, pues la colaboración entre pares apoya el desarrollo de los y las estudiantes al generar conflictos cognitivos y por consiguiente la construcción del aprendizaje”(p. 22), como la importancia de comprender, interpretar, conceptualizar y percibir los signos escritos o grafías. Donde la lectura y la escritura no debe ser papel solamente de las instituciones educativas, ya que en la educación deben estar involucrados los sujetos del entorno sociocultural donde se desenvuelven los estudiantes. "En lugar de un niño que espera pasivamente el reforzamiento externo de una respuesta producida poco menos que al azar, aparece un niño que trata activamente de comprender la naturaleza del lenguaje que se habla a su alrededor, y que, tratando de comprenderlo, formula hipótesis, busca regularidades, pone a prueba su anticipaciones, y se forja su propia gramática. En lugar de un niño que recibe de a poco un lenguaje enteramente fabricado por otros, aparece un niño que reconstruye por sí mismo el lenguaje, tomando selectivamente la información que le provee el medio" (Ferreiro, 1979, p. 22)

Siguiendo la línea de autor, afirma que el "aprendizaje de la lectura y de la escritura involucra comprensión, por ello la copia no favorece el desarrollo de pensamiento crítico y muchas veces no es más que la reproducción de figuras $\sin$ sentido. Es entonces fundamental fomentar que la persona se arriesgue a manifestar lo que piensa y lo que siente, y que utilice los dibujos y las palabras como recursos para la libre expresión”.

Daniel Cassany y sus aportes sobre lengua como la mejor herramienta para desenvolvernos en la vida, para enfrentarnos a la sociedad, para expresarnos, para comprender, para desarrollarnos como seres humanos, esta va ligada y es un punto importante en la formación de los niños, jóvenes y adultos, es un apoyo en la comunicación, pues los seres humanos nos desenvolvemos en una sociedad letrada, en la cual todos somos dependientes de todos y que la requerimos para acuerdos, para dar a conocer ideas, para reflexionar, cuestionar y un sinfín de aspectos que nos involucran como grupo. "En el desarrollo del niño como ser social, la lengua desempeña 
En el ámbito escolar, las habilidades de lectura y escritura, como el desarrollo

de la escucha y el habla, no deben ser sólo objetivos curriculares; estas habilidades deben transformarse en herramientas que favorezcan la construcción de conocimientos. la función más importante. La lengua es el canal principal por el que se le trasmiten los modelos de vida, por el que aprende a actuar como miembro de una "sociedad" - dentro y a través de los diversos grupos sociales, la familia, el vecindario, y así sucesivamente - y adoptar su "cultura", sus modos de pensar y de actuar, creencias y sus valores” (Cassany, 2006, p. 18).

En el ámbito escolar, las habilidades de lectura y escritura, como el desarrollo de la escucha y el habla, no deben ser sólo objetivos curriculares; estas habilidades deben transformarse en herramientas que favorezcan la construcción de conocimientos. Esto refiere que un usuario de la lengua debe dominar las habilidades comunicativas (hablar, escuchar, leer y escribir), para comunicarse con eficacia en todas las situaciones de la vida cotidiana. Por eso la escuela debe desarrollar propuestas metodológicas y didácticas para potenciarlas desde un punto de vista comunicativo.

Los estudiantes inician las habilidades lingüísticas con la oralidad que es una forma de producir, para acercarse a la comunicación con los demás, por eso desde que empiezan a hablar se están comunicando con quienes los rodean; cuando llegan a la escuela, llevan conocimientos que los ayudan a comenzar su proceso de lectura y escritura.

Es importante que reconozcamos la importancia del contexto, la identidad y la práctica en la lectura y la escritura y que prestemos atención a la manera en que la gente le confiere sentido a su vida a través de prácticas cotidianas que no suelen ser reconocidas en la lectura y la escritura; y aunque no se trate de sustituir las prácticas escolares por las cotidianas, habría que acercar más la escuela a las necesidades de la gente y esto implica preguntarnos qué tipo de lectores y escritores queremos producir y para qué propósitos. Para contestar a esta pregunta no nos queda sino reconocer la multiplicidad de lectura y escritura e incorporar a nuestra experiencia docente esta dimensión de lo letrado que se interesa por lo que la gente hace con los textos (Cassany 2009, p. 25).

\section{Estrategias Pedagógicas}

Al reflexionar sobre las prácticas en el aula, podemos interrogarnos sobre todas aquellas estrategias que cada maestro implementa para lograr que los estudiantes mejoren su aprendizaje, Díaz y Hernández (2002) afirman que "las estrategias pedagógicas de enseñanza son medios o recursos para prestar la ayuda pedagógica ajustada a las necesidades de progreso de la actividad constructiva de los alumnos; el docente debe poseer un bagaje amplio de estrategias, conociendo qué función tienen $y$ cómo pueden utilizarse o desarrollarse apropiadamente”, para lo cual, se implementará una secuencia didáctica que se abarca cuatro talleres enfatizados en la comprensión y producción oral y escrita de forma transversal en las áreas de lengua castellana, matemáticas, ciencias sociales y ciencias naturales; adaptadas según Díaz y Hernández "según los conocimientos y los contextos, y encaminadas al logro de 
que el estudiante sea más autónomo y reflexivo".

\section{Aprendizaje significativo}

Ausubel (1976) expresa la importancia que cada estudiante debe tener en su proceso de aprendizaje "integrando nuevas tareas de aprendizaje con los conocimientos previos y la experiencia idiosincrásica, traduciendo los nuevos enunciados a sus propios lenguajes, esforzándose por cuenta propia en dominar las materias nuevas y difíciles, planteando preguntas significativas $y$ emprendiendo conscientemente los ejercicios de solución de problemas que se les asigne", hecho importante para la ejecución de la investigación, pues permite que todos participen y reflexionen sobre el proceso y así, alcanzar el objetivo. La IETL tiene como modelo pedagógico escuela activa dando relevancia a lo que el estudiante aprende debe ser funcional, el trabajo en el aula debe estar enfocado hacia las aplicaciones prácticas en la realidad, las actividades responden a los ritmos y condiciones personales de cada uno, los estudiantes aprenden observando, preguntando, trabajando, construyendo, pensando y resolviendo situaciones problemáticas que le son presentadas; la secuencia didáctica se proyecta en estos postulados y su alcancen en la comprensión y producción oral y escrita de los estudiantes.

En conclusión, los autores reafirman la importancia que desde los primeros niveles de educación primaria en afianzar la comprensión y producción oral y escrita quienes dieron pautas para plantear la secuencia didáctica, alcanzado mejora en las habilidades comunicativas de los estudiantes.

\section{Resultados y discusiones}

De acuerdo con lo anterior, se analizaron las pruebas Saber Lenguaje, Grado Tercero, resultados de los años 2016, el proyecto PILE (Proyecto Institucional de Lectura y Escritura), el cual, desde el año 2015 aporta un banco de actividades para mejorar las competencias lectoras y escritoras en todas las áreas del conocimiento.

Las pruebas Saber aportan incrementó en un $11 \%$ en el 2016 en nivel de desempeño Insuficiente, en un 6\% el nivel mínimo, frente a la reducción del $13 \%$ en el nivel Satisfactorio y un $4 \%$ en el nivel Avanzado. En el desarrollo del PILE presentan dificultades como: no seleccionar actividades propias para cada nivel, organización esporádica, la falta de compromiso por parte de algunos miembros de la comunidad educativa, selección de actividades trasversales para las diferentes asignaturas que contribuyan a afianzar las habilidades.

\section{Prueba de entrada}

La prueba aplicada a los estudiantes se desarrolló teniendo como propósito determinar los niveles iniciales de lectura y escritura a partir de la comprensión y producción oral $\mathrm{y}$ escrita. Teniendo cuenta que los estudiantes de acuerdo a su edad han desarrollado principalmente su oralidad se inició estimulando la imaginación y preguntando sobre lo que pueden predecir sobre el título de la lectura 
"El Oso Santilín", posteriormente se dio comienzo a la lectura guiada en voz alta con la participación total de los estudiantes; al terminar la lectura los estudiantes usan su creatividad para continuar con la secuencia del cuento y finalizarlo mediante un escrito con sus propias palabras teniendo en cuenta sus partes; se continuó con el desarrollo del taller de acuerdo a la guía diseñada donde los estudiantes contestan algunos cuestionamientos centrado en las ideas y la información que está explícitamente expuesta en el texto; otras teniendo en cuenta lo que se comprende por medio de relaciones y asociaciones el significado local o global del texto y para terminar intervienen los saberes previos del lector, su criterio y el conocimiento de lo leído y así emitir juicios valorativos de lo que sucedido en el texto. Finalmente se realizó un conversatorio donde de forma oral los estudiantes expresaron y compartieron las experiencias y opiniones vividas durante el desarrollo de la actividad.

\section{Secuencia didáctica}

En la secuencia didáctica se plantearon actividades de comprensión y producción oral y escrita articuladas con las diferentes áreas: lengua castellana, matemáticas, ciencias naturales $\mathrm{y}$ ciencias sociales; donde se fortalecieron los procesos de comprensión $\mathrm{y}$ producción teniendo como referencia las habilidades y micro habilidades planteadas en las mallas curriculares del ministerio de educación para lenguaje del grado tercero. La secuencia se evaluó mediante la rúbrica de análisis.
La secuencia se direccionó por medio de talleres en las diferentes áreas así:

Lengua Castellana: Se desarrolló el taller "leemos, comprendemos y aprendemos" en tres actividades:

Interpretación de imágenes de un cuento en friso: Sé diseñó para despertar el interés hacia la lectura, por medio de una historieta presentada con imágenes, donde cada estudiante observó las imágenes y escribió lo que imaginó que sucedía en forma de cuento, teniendo en cuenta experiencias vividas. $\mathrm{Al}$ terminar, el escrito cada estudiante comentó una experiencia que le había ocurrido, parecida a lo visto en las imágenes.

Lectura silenciosa, individual: Se buscó en internet la imagen de una persona y se hizo la descripción, se indaga a los estudiantes sobre el texto descriptivo, se invita a los estudiantes a imaginar de qué se hablará en la lectura., se diseñó un pequeño cuestionario con preguntas acerca de la descripción. Al recibir la fotocopia los estudiantes observaron la foto, nombraron las cualidades físicas de la persona e hicieron comentarios acerca de lo que trataría la lectura. En seguida cada estudiante realizó la lectura en silencio, después de terminar la lectura se hizo la deducción de algunas palabras nuevas para ellos y se hicieron comentarios acerca de los sentimientos de la persona. Por último cada estudiante hizo la descripción, utilizando sus propias palabras y desarrollaron el cuestionario dado.

Lectura guiada en voz alta: Se buscó en internet una narración, la cual 
fue copiada en Word para imprimirlo, dejándolo sin terminar, para que los estudiantes practicaran la producción de texto, narrando un final inventado por cada uno; también se diseñó un cuestionario de análisis y reflexión, teniendo en cuenta la lectura.

Matemáticas: Se desarrolló el taller "juguemos con la matemática" distribuido cuatro (4) estaciones o mesas de trabajo con actividades donde cada grupo de estudiantes pasaba por cada una de ellas y desarrollaban la actividad propuesta. Las actividades estaban distribuidas así:

Adivinar y comprobar: En esta estación los estudiantes individualmente leen, interpretan la información, y describen la posible solución y finalmente en grupo argumentan la respuesta.

Gimnasia matemática: La estación les permitió: realizar la lectura de la situación, hacer inferencias $y$ suposiciones, realizar comparaciones, organizar la información y sustentar argumentado su respuesta.

Ejercito mi mente: En esta estación los estudiantes realizaron lectura comprensiva, observaron imágenes y la asociaron con el contenido, usaron algunas estrategias de lectura que le permiten solucionar problemas de comprensión y responder los cuestionamientos para concluir con la respuesta y así argumentar su solución.

Letras y números: este ejercicio les permitió anticipar, inferir y concluir desde diferentes perspectivas y además sustentar su respuesta.
Ciencias Sociales: Se desarrolló el taller "un amigo ama en todos los momento" los estudiantes demostrarán la facilidad para empatizar en cualquier grupo y su capacidad para sensibilizarse ante cualquier situación; para esta actividad se desarrolló así:

- Se indaga en los estudiantes sobre el concepto de la amistad y entre todos se conceptualiza, observan un video donde se evidencia el valor de la amistad.

- Después de observar el video se recogen las opiniones de los estudiantes. se realizan preguntas y cuestionamientos a los estudiantes sobre el video.

- Se reparte a los estudiantes pedazos de cartulina de colores y cada uno escribirá los momentos en los que se evidenció la verdadera amistad y porque lo hacía. Cada estudiante lee sus reflexiones y las pegan en la pared.

- Realizar un friso donde se evidencien las escenas más impactantes del cortometraje y exponerlo ante sus compañeros.

\section{- Desarrollo de caso situación}

Ciencias Naturales: Se desarrolló el taller "cuidemos nuestro páramo" teniendo en cuenta las siguientes actividades:

Sensibilización: Los estudiantes asociaron saberes previos, con los proyectados en el video y los expuestos por la docente.

Desarrollo: Los estudiantes realizaron la producción textual "cómo cuido mi páramo "mediante una narración 
y la elaboración de un rompecabezas ecológico con cuestionamientos sobre la fauna, flora y situación ambiental de los páramos.

Aplicación: Participaron en desarrollo de un rally de observación, en la cconstrucción, grabación y proyección de cortometraje y finalmente socializaron y evaluaron la actividad.

\section{Prueba de salida}

La prueba de salida se realizó una semana después de terminar la aplicación de la secuencia didáctica. El texto que se utilizó para esta prueba fue "El Niño y los Clavos" tomado de (https://www. guiainfantil.com/1428/cuento-infantilel-nino-y-los-clavos.html). El objetivo de esta prueba fue evidenciar los avances en el desarrollo de la comprensión y producción oral y escrita; los niveles iniciales y finales en los estudiantes, después de la implementación de la secuencia didáctica.

Al aplicar la prueba se inició con la anticipación sobre el título de la lectura teniendo en cuenta los conocimientos previos del estudiante. Se continúa con la lectura guiada en voz alta con la participación de algunos los estudiantes; al finalizar la lectura los estudiantes usan su imaginación para cerrar la secuencia del cuento mediante un escrito con sus propias palabras el cuento teniendo en cuenta los personajes, ambiente, tiempo y que logre resolver los elementos que ha ido colocando a lo largo del texto; se continuó con el desarrollo del taller de acuerdo a la guía diseñada donde los estudiantes contestan algunos cuestionamientos centrados en las ideas y la información que está explícitamente expuesta en el texto; otras teniendo en cuenta lo que se comprende por medio de relaciones y asociaciones el significado local o global del texto y para terminar intervienen los saberes previos del lector, su criterio y el conocimiento de lo leído y así emitir juicios valorativos de los sucedido en el texto. Se continuó con la representación por medio de dibujos del cuento teniendo en cuenta escenas, pero también siguiendo la progresión temática del texto. Finalmente se realizó un conversatorio donde oralmente los estudiantes expusieron sus dibujos expresando y compartieron las experiencias, sentimientos y opiniones en torno a la lectura y las experiencias vividas durante el desarrollo de la actividad.

La secuencia didáctica fue diseñada teniendo en cuenta los aportes de Hernández "las estrategias pedagógicas deben adaptarse según los conocimientos y los contextos, estar encaminadas al logro de que el estudiante sea más autónomo y reflexivo" (Díaz, 2002, p.142) y también con un aprendizaje significativo con Ausubel "Un aprendizaje significativo requiere tanto de una actitud de aprendizaje significativo como la presentación al estudiante de un material potencialmente muy significativo. Esto quiere decir que el propio material de aprendizaje se pueda relacionar de una manera no arbitraria y no literal con cualquier estructura cognitiva apropiada y pertinente (que posea un significado lógico) y que la estructura de la persona concreta que aprende contenga ideas de anclaje pertinentes con las que el 
nuevo material se pueda relacionar. $\mathrm{La}$ interacción entre significados potencialmente nuevos e ideas pertinentes en la estructura cognitiva del estudiante da lugar a significados reales o psicológicos; puesto que la estructura cognitiva de cada persona que aprende es única, todos los nuevos significados adquiridos son, forzosamente únicos" (Ausubel, 2000, p.25).

\section{Conclusiones}

La investigación planteó la necesidad de mejorar las habilidades lectoras y escritoras en los estudiantes de los grados segundo y tercero de las sedes Peña de Águilas y Libertad de la IET La Libertad. Teniendo en cuenta la preocupación que desde las políticas nacionales, departamentales, municipales e institucionales se dan, en busca de alcanzar mejores desempeños en la comprensión oral y escrita y en la producción oral y escrita.

La comprensión oral y escrita se presenta en afianzar adquisición del código escrito y la comprensión al leer y escuchar, mediante el acercamiento a textos como anécdotas, chistes, cuentos, fábulas, manuales, noticias, canciones, poemas, rimas, adivinanzas, invitaciones, cartas, entre otros. La lectura en voz alta en ocasiones fue una situación conflictiva para el estudiante, por ser delante del docente y los compañeros, hecho que no pone en evidencia a los estudiantes más tímidos o a aquellos que consideran que pueden ser juzgados por no leer a la misma velocidad y con una pronunciación tan buena como la de otros. Por eso, se hizo necesario reforzar valores como la solidaridad y el respeto, realizando un trabajo cooperativo, en el que los estudiantes se corrijan con respeto en caso de equivocaciones durante la lectura.

Los procesos de producción oral y escrita seenfatizan en escribiry hablar; la escritura tiene que ver con el fortalecimiento del código escrito, los estudiantes reconocen que sus producciones escritas pueden ser leídas por otros, se refuerza aspectos como legibilidad de sus trazos y el uso correcto de las normas ortográficas, uso del diccionario que, además, favorecerá el reconocimiento de las letras y la ampliación del vocabulario. En relación con la producción oral, uno de los retos que puede presentarse es la escasa participación de los estudiantes en discusiones donde sea necesaria la expresión de sus puntos de vista frente a los temas abordados.

Mediante la aplicación de la secuencia didáctica se evidenció el mejoramiento en el uso de habilidades para comprender y analizar la información que se obtiene por medio de la lectura, involucrando los conocimientos previos y el entorno sociocultural, generando nuevos conocimientos importantes para la vida, y transformándolos en competencias para producir textualmente sus propios escritos.

Para realizar la secuencia didáctica se desarrolló un aprendizaje con sentido y significado fortaleciendo en ellos la comprensión, el análisis, la construcción y la capacidad de crear y de producir de los estudiantes; ellos se preguntarán el porqué de algunas
La investigación planteó la necesidad de mejorar las habilidades lectoras y escritoras en los estudiantes de los grados segundo y tercero de las sedes Peña de Águilas y Libertad de la IET La Libertad. 
situaciones, facilitando así el acceso al conocimiento, también dando la oportunidad a los estudiantes para que expresen sus vivencias y relaciones con el entorno donde se desenvuelven, y así de esta forma lleguen a crear su nuevo conocimiento y esto lo evidenciamos cuando los estudiantes realizan sus narraciones, descripciones, explicaciones y producciones.

Se pudo observar que la comprensión y producción oral y escrita no solamente le corresponde al área de Lengua Castellana, pues al involucrarla en las diferentes áreas del plan de estudios permite mejorar los conocimientos y afianzar las habilidades de manera transversal.

Los resultados después de implementar la secuencia didáctica y evaluar los niveles finales en la muestra poblacional arrojaron un avance significativo en la compresión, predicción de hechos, identificar información implícita y explícita en un texto, en su gran mayoría identifican la clase de texto que leen, sus partes y características, relacionan personajes, con los hechos y contextos. Algunos estudiantes infieren significados y los clasifica, defienden sus ideas ante sus compañeros. Las producciones orales y escritas reflejan ideas organizadas, usan conectores adecuadamente. Se evidenció en algunos que el lenguaje usado lo toma de diario vivir y con base a ello redactan sus producciones, se evidencia aún en algunos estudiantes timidez al participar en conversaciones o participar en el desarrollo de las actividades propuestas.

Es importante reconocer que lo anterior se logrará únicamente si como docentes, realizamos una autorreflexión sobre nuestro quehacer pedagógico, generamos un cambio y planteamos actividades que despierten el interés y la curiosidad del estudiante, donde este opine y aporte ideas; al ser guiado por el docente pueda obtener un aprendizaje significativo, permitiendo que los estudiantes aprendan gradualmente en un entorno interactivo, compartido y organizado entre quien enseña y quien aprende.

\section{Referencias}

Ausubel, D. P. (2000). Adquisición retención del conocimiento. Barcelona: Paidós Editorial.

Ávila, P. (02 de Julio de 2009). Leer bien para escribir mejor: estrategias docentes para la enseñanza de la lectura y la escritura. España: UNED-España.

Cassany, D. (2006). Tras las líneas: sobre lectura contemporánea. Barcelona: Anagrama.

Díaz, A. (2002). Estrategias Docentes para un Aprendizaje Significativo Una interpretación constructivista. México: McGraw-Hill. 
DNP- Departamento Nacional de Planeación. (2015). Plan Nacional de Desarrollo 2014-2018 Todos por un Nuevo País, Tomo 1. Bogotá, D.C., Colombia: Imprenta Nacional de Colombia.

Elliot, J. (1990). El cambio educativo desde la investigación - acción. Madrid: Ediciones Morata, S. L.

Escamilla, A. Unidades Didácticas: una propuesta de trabajo en el aula: Zaragoza: Edelvives. 1993.

Ferreiro, E., \& Teberosky, (1979). Los sistemas de escritura en el desarrollo del niño. México: Siglo veintiuno.

Flórez, R. (1997). Hacia una pedagogía del conocimiento. MacGraw Hill, Santafé de Bogotá.

Instituto Colombiano para la Evaluación de la Educación (ICFES). (2016). Resumen Ejecutivo Colombia en PISA 2015. Bogotá: ICFES.

Ministerio de Educación Nacional (2011). Cartillas de Actividad diagnóstica

Ministerio de Educación Nacional. (2015). Colombia, la mejor educada en el 2025; Líneas estratégicas de la política educativa del Ministerio de. Bogotá: MEN.

Ministerio de Educación Nacional. 1998. Lengua castellana: lineamientos curriculares: áreas obligatorias y fundamentales Colombia. Ministerio de Educación Nacional.

Ong, W, (1987). Oralidad y escritura: tecnologías de la palabra. Ediciones Fondo de Cultura Económica.

Pulido, D., Nájar, O., \& Guesguan, L. (2016). Vivamos la innovación de la inclusión de dispositivos móviles en la educación. Praxis « Saber, 7(14), 115 - 140. https:// doi.org/10.19053/22160159.5220

Teberosky, A. (2002). Los sistemas de escritura. Congreso Mundial de Lecto-escritura, celebrado en Valencia. Universidad de Barcelona

Trevor, C. 1992. Enseñanza de la comprensión lectora. Ediciones Morata.

UNESCO. 1998. Los docentes y la enseñanza en un mundo en mutación.

Valverde, Y. (2014). Lectura y escritura con sentido y significado, como estrategia de pedagógica en la formación de maestros. Fedumar Pedagogía y Educación, 71-104.

Villalonga, M. (2014). Comprensión lectora en niños de escolaridad primaria de San Miguel de Tucumán que viven en contextos de pobreza. Población y sociedad, 149160. 